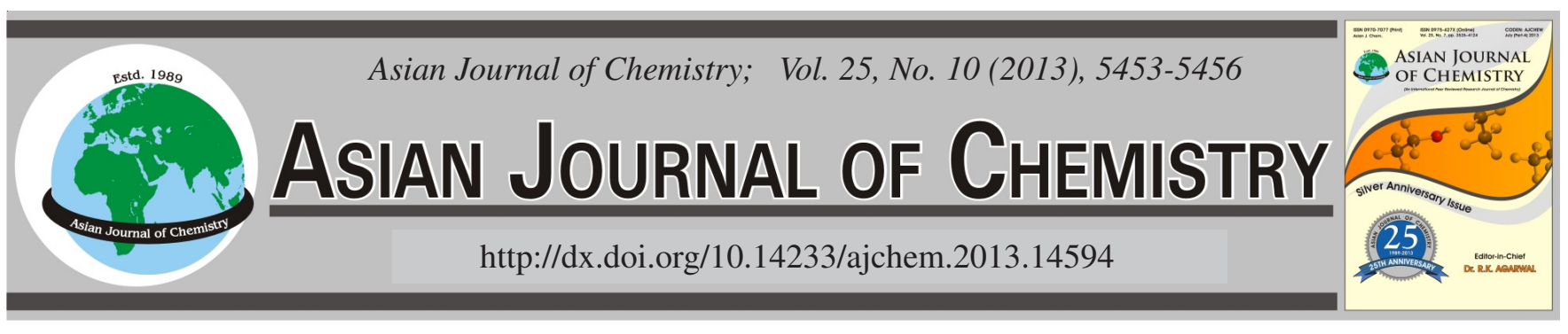

\title{
In Vitro Antioxidant and Anticancer Activities of the Extract from Paper Mulberry (Broussonetia papyrifera L.) Fruit
}

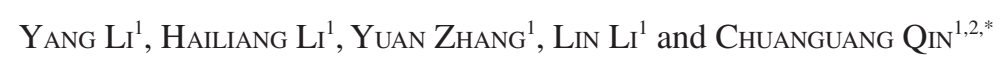

${ }^{1}$ School of Life Sciences, Northwestern Polytechnical University, Xi'an, P.R. China

${ }^{2}$ Key Laboratory on Space Applied Physics and Chemistry of Ministry of Education; Key Laboratory on Macromolecular Science \& Technology of Shaanxi Province; Department of Applied Chemistry, School of Natural and Applied Sciences, Northwestern Polytechnical University, Xi' an 710129, P. R. China.

*Corresponding author: Fax: +86 29 88460332; Tel: +86 13991392191; E-mail: qinchg@nwpu.edu.cn; liyaaang@gmail.com

(Received: 17 September 2012;

Accepted: 13 April 2013)

AJC-13228

The antioxidant and anticancer activities of ethanolic extract of paper mulberry (Broussonetia papyrifera L.) fruit were investigated in this
study. The total phenolic content of the extract was found to be $148.79 \pm 0.91 \mathrm{mg}$ gallic acid equivalents $\mathrm{g}^{-1}$ of lyophilized extract. The
extract showed reducing power and was a scavenger of DPPH radicals. The extract inhibited the proliferation of human osteosarcoma
MG63 cells, which associated with apoptosis and cell cycle arrest. The antioxidant and anticancer activities of the extract showed a dose-
dependent increase in the assays. These studies demonstrated that the ethanolic extract of paper mulberry fruit is a potent antioxidant and
exerts promising anticancer activity.

Key Words: Antioxidant activity, Anticancer activity, Phenolic compound, Paper mulberry fruit, Broussonetia papyrifera L.

\section{INTRODUCTION}

In addition to the protective effects of endogenous antioxidants, the consumption of dietary antioxidants appears to be of great importance in preventing chronic diseases that have a close relationship with the oxidative damage ${ }^{1}$. Phenolic compounds are a large class of bioactive secondary metabolites, which are widely distributed in fruits and vegetables, represent the most abundant antioxidants in the diet ${ }^{2}$. Many scientists have focused their attentions on phenolic compounds to study the antioxidant activity. In recent years, much attention has also been paid to potential anticancer components from natural products. Epidemiological studies have indicated that ingestion of phenolic compounds could reduce the risk of certain cancers ${ }^{3}$. Therefore, as development activity increases in this area, it is not surprising that phenolic compounds have gained tremendous interest.

Paper mulberry, which scientific name is Broussonetia papyrifera $\mathrm{L}$., belongs to the family of Moraceae, is a deciduous tree or shrub, which grows naturally in Pacific countries such as China, Burma, Polynesia and USA. Fruit of paper mulberry is edible and is a good source of sugars, acids and phenolic compounds. The fruit is used for treatment of impotence and ophthalmic disorders in Chinese folk remedy ${ }^{4}$. However, studies of phenolic compounds from paper mulberry fruit have been rarely reported.

The objective of this study was to investigate the in vitro antioxidant activity of paper mulberry fruit extract and its cytotoxicity to human osteosarcoma MG63 cells.

\section{EXPERIMENTAL}

Fresh fruits of paper mulberry were collected from Beilin district of Xi'an, China during July 2011 and identified at the School of Life Sciences, Northwestern Polytechnical University, Xi'an, China. A voucher specimen is preserved in the same place.

Preparation of paper mulberry fruit extract: Paper mulberry fruits $(50 \mathrm{~g})$ were immersed in $1.75 \mathrm{~L}$ of $80 \%$ ethanol at $40{ }^{\circ} \mathrm{C}$ for $2 \mathrm{~h}$. The extract was filtered through filter paper and then evaporated at $40{ }^{\circ} \mathrm{C}$ in rotary evaporator (EYELA, N1001, Japan) to obtain concentrated solution. Subsequently, the concentrated solution was purified by passing through a $2 \mathrm{~g}$ sorbent weight $\mathrm{C} 18$ solid phase extraction (SPE) cartridge (AGELA, China), previously activated with methanol followed by deionized water. Washing the SPE cartridge with $10 \mathrm{~mL}$ of deionized water and ethyl acetate in sequence, then the extract was eluted with methanol. The methanol solution was dried by rotary evaporator at $40{ }^{\circ} \mathrm{C}$. The dry extract was resuspended in deionized water and lyophilized in a lyophilizer (CHRIST, Alpha 1-2, Germany) to obtain lyophilized paper mulberry fruit extract. The extract was placed in a plastic bottle and stored at room temperature.

Determination of total phenolic content: Total phenolic content was determined using the Folin-Ciocalteu method ${ }^{5}$. To a $10 \mathrm{~mL}$ volumetric flask, $0.1 \mathrm{~mL}$ of $3.2 \mathrm{mg} \mathrm{mL}^{-1}$ sample solution, $1.5 \mathrm{~mL}$ of $1 \mathrm{~mol} \mathrm{~L}^{-1}$ Folin-Ciocalteu reagent, $2 \mathrm{~mL}$ of $12.5 \%$ sodium carbonate solution and $6.4 \mathrm{~mL}$ deionized 
water were added and then mixed. The absorbance was measured at $765 \mathrm{~nm}$ with a UV-visible spectrophotometer (HITACHI, F2300, Japan) after the mixture was incubated for $2 \mathrm{~h}$ at room temperature. Total phenolic content was calculated as gallic acid equivalent (GAE) based on the standard curve of gallic acid. The data were expressed as milligram GAE $\mathrm{g}^{-1}$ of lyophilized paper mulberry fruit extract.

Measurement of reducing power: Reducing power was determined as described by Oyaizu ${ }^{6}$, but modified slightly. $1 \mathrm{~mL}$ of sample solution at different concentrations, $2.5 \mathrm{~mL}$ of $0.2 \mathrm{~mol} \mathrm{~L}^{-1}$ phosphate buffer, $\mathrm{pH} 6.6$ and $2.5 \mathrm{~mL}$ of $1 \%$ potassium ferricyanide were added to a glass tube. The mixture was mixed well and incubated at $50{ }^{\circ} \mathrm{C}$ for $20 \mathrm{~min}$. Subsequently, $2.5 \mathrm{~mL}$ of $10 \%$ trichloroacetic acid was added to the mixture and then centrifuged at $6000 \mathrm{rpm}$ for $10 \mathrm{~min} .2 .5 \mathrm{~mL}$ of the supernatant was taken and mixed with $2.5 \mathrm{~mL}$ deionized water and $0.5 \mathrm{~mL}$ of $0.1 \%$ ferric chloride. After $10 \mathrm{~min}$, the absorbance was measured at $700 \mathrm{~nm}$ by spectrophotometer. Ascorbic acid was used as positive control. High absorbance of the reaction mixture indicates high reducing power.

DPPH radical scavenging activity: DPPH free radical scavenging activity was determined according to the method of Shimada et $a l^{7}$. $0.1 \mathrm{~mL}$ of sample solution at different concentrations and $0.2 \mathrm{~mL}$ of $25 \mu \mathrm{mol} \mathrm{L} \mathrm{L}^{-1} \mathrm{DPPH}$ ethanol solution were mixed and stand for $20 \mathrm{~min}$ in the dark at room temperature. The absorbance was then measured at $517 \mathrm{~nm}$ by spectrophotometer. Ascorbic acid was used as positive control. The free radical scavenging activity was calculated as inhibition of DPPH radical as follows:

$$
\text { Inhibition }(\%)=\left(\frac{\mathrm{A}_{517(\text { Control })}-\mathrm{A}_{517(\text { Sample })}}{\mathrm{A}_{517(\text { Control })}}\right) \times 100 \%
$$

Cell line and culture: Human osteosarcoma cell line (MG63) was purchased from China Centre for Type Culture Collection, Chinese Academy of Sciences. MG63 cells were cultured in MEM medium ( $\mathrm{pH} 7.4$ ), supplemented with 100 $\mathrm{U} \mathrm{mL}^{-1}$ penicillin, $100 \mu \mathrm{g} \mathrm{mL} \mathrm{m}^{-1}$ streptomycin, $2 \mathrm{mmol} \mathrm{L}^{-1} \mathrm{~L}-$ glutamine and $10 \%$ heat inactivated fetal bovine serum. Cells were maintained at $37{ }^{\circ} \mathrm{C}$ in a humidified $5 \% \mathrm{CO}_{2}$ incubator.

Cell viability assay: The viability of the cells was assessed by 3-(4,5-dimethylthiazol-2-yl)-2,5-diphenyltetra zolium bromide (MTT) assay according to the method described by Prasad et al. ${ }^{8}$. MG63 cells were collected, $1 \times 10^{5}$ cells $\mathrm{mL}^{-1}$ were added into 96-well plates in $100 \mu \mathrm{L}$ volumes and cultured overnight. Then different concentrations of the extract were added separately with $100 \mu \mathrm{L}$ and the cells were incubated for 24 and $48 \mathrm{~h}$ followed by remove of medium. Subsequently, $200 \mu \mathrm{L}$ MEM medium and $20 \mu \mathrm{L}$ of $5 \mathrm{mg} \mathrm{mL}^{-1}$ MTT reagent were added. After incubating at $37{ }^{\circ} \mathrm{C}$ for $4 \mathrm{~h}$, the medium was removed and $150 \mu \mathrm{L}$ DMSO was added to each well. Cell proliferation was estimated by measuring the absorbance at $570 \mathrm{~nm}$ using an ELISA plate reader. The inhibition of cell proliferation was calculated using the following formula:

$$
\text { Inhibition }(\%)=\left(\frac{\mathrm{A}_{570(\text { Control })}-\mathrm{A}_{570(\text { Sample })}}{\mathrm{A}_{570(\text { Control })}}\right) \times 100 \%
$$

Hoechst 33258 staining: MG63 cells were stained with Hoechst 33258 as the method of Liu et al. ${ }^{9}$ In brief, MG63 cells were seeded in 24 -well plates with $1 \mathrm{~mL}$ of $1 \times 10^{5}$ cells $\mathrm{mL}^{-1}$ and cultured overnight. The cells were then treated with different concentrations of the extract for $24 \mathrm{~h}$. After removing the medium, the cells were fixed with methanol/glacial acetic acid (3/1, v/v) for 10 min and washed twice with PBS. Finally, the cells were stained with Hoechst 33258 for 5 min. A fluorescence microscope (NIKON, 80i, Japan) was used to observe the Hoechst 33258 staining MG63 cells.

Flow cytometry analysis: MG63 cells treated with the extract were analyzed by flow cytometry as described by Peng et al. ${ }^{10}$. Briefly, MG63 cells were harvested by centrifugation at the density of $1 \times 10^{6}$ cells $\mathrm{mL}^{-1}$ after treated with the extract for $24 \mathrm{~h}$ and washed with cool PBS by twice. After that, cells were treated with $25 \mu \mathrm{g} \mathrm{mL} \mathrm{m}^{-1} \mathrm{RNase} \mathrm{A}$ at $37^{\circ} \mathrm{C}$ for $0.5 \mathrm{~h}$ and stained with $50 \mu \mathrm{g} \mathrm{mL}^{-1}$ propidium iodide solution for $0.5 \mathrm{~h}$ in the dark. Flow cytometer (BD, FACSCalibur, USA) was used to measure the fluorescence intensity of individual cells.

Statistical analysis: Results were expressed as the mean $\pm \mathrm{SD}$ of three independent experiments. Analysis of variance was performed using One-way ANOVA procedures (Prism 5, GraphPad Software, USA). A value of $p<0.05$ was regarded as being significant. The $\mathrm{IC}_{50}$ value was defined as the concentration of the sample that reduces the effect by half and was calculated by regression analysis.

\section{RESULTS AND DISCUSSION}

Ethanol extract of paper mulberry fruit: The fruits were extracted with $80 \%$ ethanol and the extract was purified by washing with deionized water and ethyl acetate. The extract comprised 7 phenolic compounds, which were $\left(7 R^{*}, 8 S^{*}, 8^{\prime} R^{*}\right)$ 7",8"-erythro-3'-methoxy-7'-oxo-4,4",7",9,9"'-pentahydroxy4',8":7,9'-bis-epoxy-8,8'-sesquineolignan, 2-(4-hydroxyphenyl)propane-1,3-diol-1-O- $\beta$-D-glucopyranoside, arbutine, cissyringin, cis-coniferin, curculigoside $\mathbf{I}$ and curculigoside $\mathrm{C}^{11}$ and presented $148.79 \pm 0.91 \mathrm{mg} \mathrm{GAE} \mathrm{g}^{-1}$ lyophilized extract total phenols. Some scientists investigated the extracts from different parts of paper mulberry ${ }^{12,13}$, but there are few reports about the ethanol extract from the fruit. The total phenolic content of the extract was much higher than that of ethanol extract from mulberry fruits at $0.959-2.57 \mathrm{mg} \mathrm{GAE} \mathrm{g}^{-1}$ dry sample $^{14}$ and ethanol extract of blackberry at $12.00-25.78 \mathrm{mg}$ GAE g ${ }^{-1}$ dry sample ${ }^{15}$.

Phenolic compounds from medicinal herbs and dietary plants possess bioactivities and play an important role in prevention of cancer. They have complementary and overlapping mechanisms of action, including antioxidant activity, scavenging free radicals, modulation of carcinogen metabolism and inducing apoptosis and cell-cycle arrest of tumor cells ${ }^{16}$.

Reducing power of the extract: The extract donated the electrons and the $\mathrm{Fe}^{3+}$ was reduced to $\mathrm{Fe}^{2+}$ (Fig. 1). The reducing power of the extract was concentration-dependent and increased to 1.07 at $266.67 \mu \mathrm{g} \mathrm{mL}^{-1}$. Some phenolic compounds extracted from other plant also showed reducing power, which increased with increasing amount of samples ${ }^{17}$. According to the result, it is suggested that the extract had the ability of donating electrons to react with free radicals to convert them into more stable species and to terminate the free radical chain reactions. 


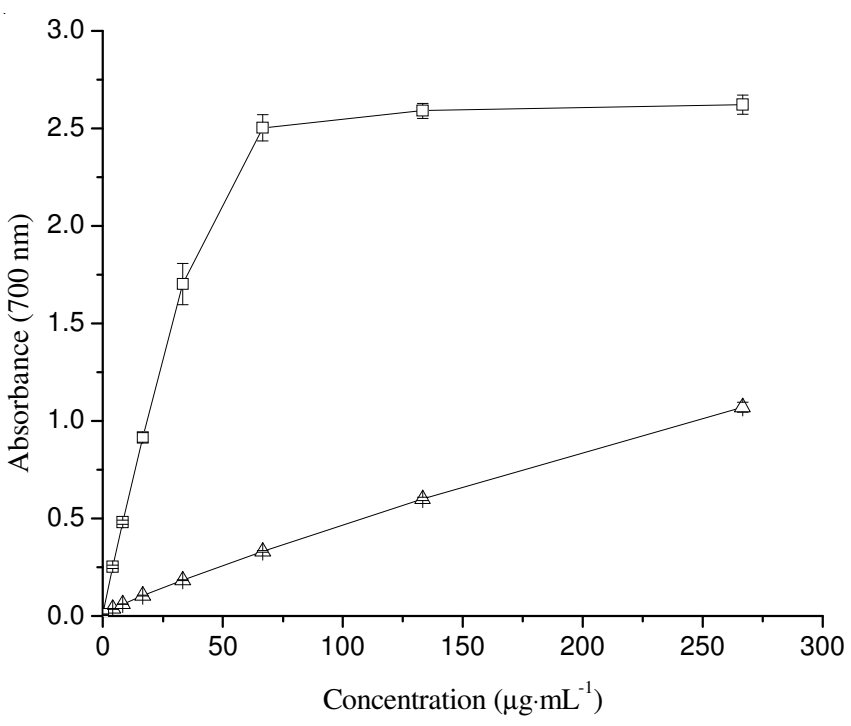

Fig. 1. Reducing power of paper mulberry fruit extract. Data is expressed as mean $\pm \operatorname{SD}(n=3)$. Values in different groups are significantly different from control, $p<0.05$. $(\Delta)$ paper mulberry fruit extract; () ascorbic acid

DPPH radical scavenging activity: The DPPH radical does not exist in the body, but it is widely used to evaluate the free radical scavenging effect of natural extracts or synthetic compounds ${ }^{18}$. In this assay, the extract scavenged DPPH radicals effectively with dose-dependent manner (Fig. 2). At final concentration of $533 \mu \mathrm{g} \mathrm{mL}^{-1}$, the scavenging ability of the extract was $90.54 \pm 1.71 \%$. The $\mathrm{IC}_{50}$ value of the extract was 156.3 $\mu \mathrm{g} \mathrm{mL} \mathrm{m}^{-1}$, which was lower than that of ethanol extract from mulberry fruit of five cultivars at 349, 180.7, 330.3, 244.3 and $430.1 \mu \mathrm{g} \mathrm{mL}{ }^{-1}$, respectively ${ }^{14}$. DPPH free radical is very stable and thus implies that the extract will react with other more reactive free radicals ${ }^{19}$.

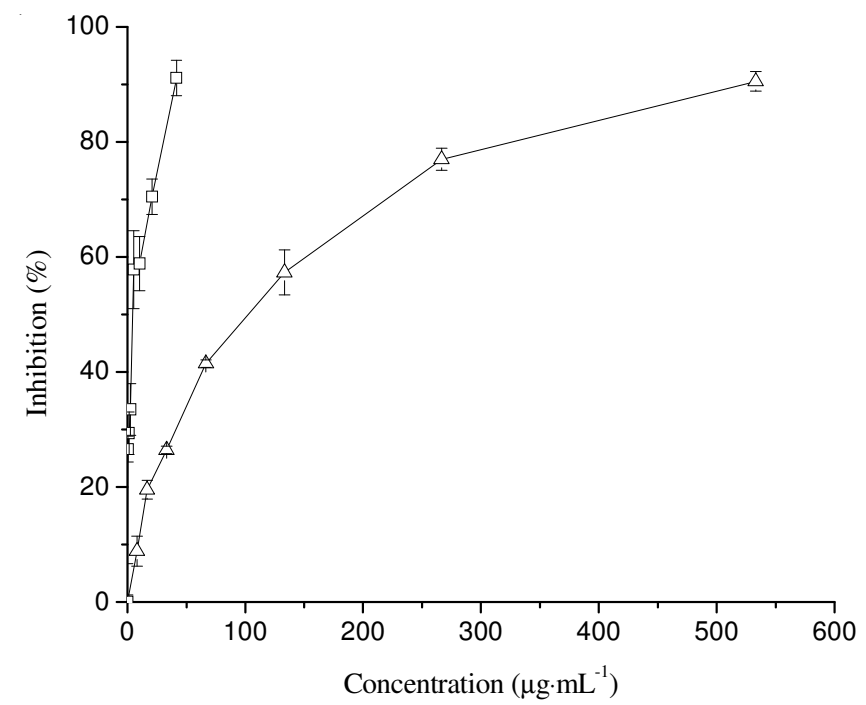

Fig. 2. Scavenging activity of paper mulberry fruit extract on DPPH radical. Data is expressed as mean $\pm \mathrm{SD}(\mathrm{n}=3)$. Values in different groups are significantly different from control, $p<0.05$. $(\Delta)$ paper mulberry fruit extract; ( $\square$ ) ascorbic acid

The results of this work indicate that the extract acts as an antioxidant and it could be attributed to the phenolic constituents. Phenolics possess one or more aromatic rings bearing one or more hydroxyl groups. In general, the phenolic $\mathrm{OH}$ is considered the primary factor for the antioxidant activity. The interreaction between antioxidants and free radicals is important in maintaining health and preventing the onset and progression of several chronic diseases such as cancer ${ }^{16,20}$.

Anticancer activity of the extract: We evaluated the effect of the extract on MG63 cells proliferation using MTT assay. Fig. 3 shows that the extract inhibited MG63 cells proliferation significantly in a time and dose dependent manner $(p$ $<0.05$ ). The inhibition of 24 and $48 \mathrm{~h}$ group increased rapidly during the concentration of $0-1600 \mu \mathrm{g} \mathrm{mL} \mathrm{m}^{-1}$ and reached the maximum at $3200 \mu \mathrm{g} \mathrm{mL}^{-1}$. In $24 \mathrm{~h}$ group, the extract of 200$3200 \mu \mathrm{g} \mathrm{mL}^{-1}$ inhibited proliferation from $5.68 \pm 1.43-95.79$ $\pm 1.85 \%$ and showed slightly weaker effect with higher $\mathrm{IC}_{50}$ value $\left(1101 \mu \mathrm{g} \mathrm{mL}^{-1}\right)$ than that of $48 \mathrm{~h}$ group $\left(924 \mu \mathrm{g} \mathrm{mL} \mathrm{L}^{-1}\right)$. Li et $a l .^{21}$ reported that ginsenoside $\mathrm{Rg} 1$, cinnamic acid and tanshinone IIA showed anticancer effect on MG63 cells with down-regulation of nucleophosmin. Thus, in order to evaluate the cause of the cytotoxicity, the effect on the induction of apoptotic cell death and the distribution of cell cycle were investigated.

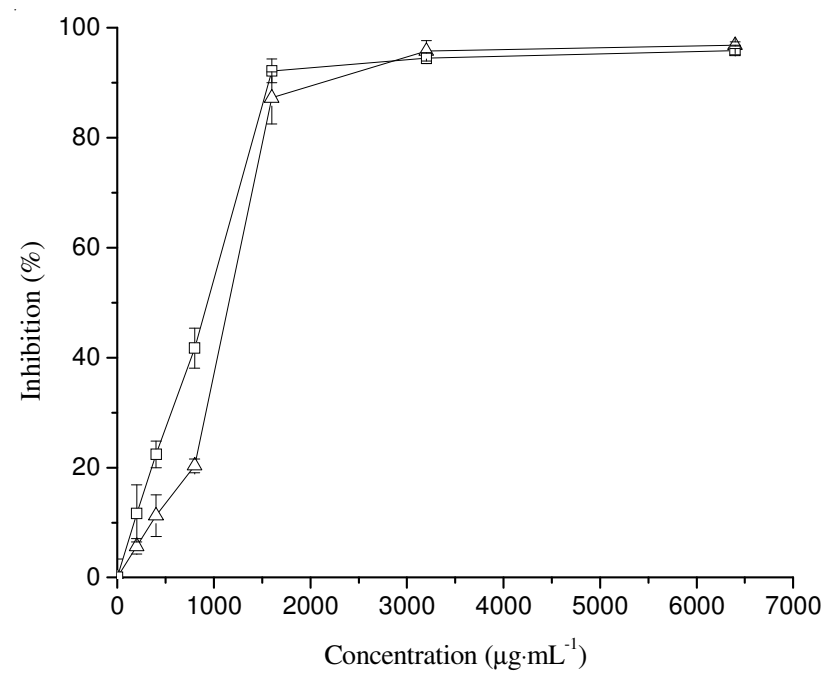

Fig. 3. Cytotoxicity induced by paper mulberry fruit extract. Data is expressed as mean $\pm \mathrm{SD}(\mathrm{n}=6)$ from one of three different experiments. Values of samples in two groups are significantly different from control, $p<0.05$. ( $\Delta$ ) 24 h group; ( $\square) 48$ h group

The cells treated with the extract showed significant morphological apoptotic changes. Compared to control cells (Fig. 4A), cell nucleus that were treated with the extract were shrunken and some cell nucleus divided to irregular fragments. The typical apoptotic features of condensed chromatin and fragmented punctate blue nuclear fluorescence were seen in extract-treated cells (Fig. 4B-D).

As shown in Fig. 5, the percentages of MG63 cells at G0/ G1 phase were $50.76 \pm 2.98 \%\left(0 \mu \mathrm{g} \mathrm{mL}^{-1}\right.$, control group $)$, $59.27 \pm 1.53 \%\left(400 \mu \mathrm{g} \mathrm{mL}^{-1}\right), 68.61 \pm 0.79 \%\left(800 \mu \mathrm{g} \mathrm{mL}^{-1}\right)$ and $79.62 \pm 1.25 \%\left(1600 \mu \mathrm{g} \mathrm{mL}^{-1}\right)$, respectively. Compared to control group, the percentage of extract-treated MG63 cells at G0/G1 phase increased significantly $(p<0.05)$. Thus, cytotoxic effect of the extract on MG63 cells was partly due to the cell cycle arrest at G0/G1 phase. It is well known that cyclin dependent kinases (CDKs) and cyclins are major molecules 

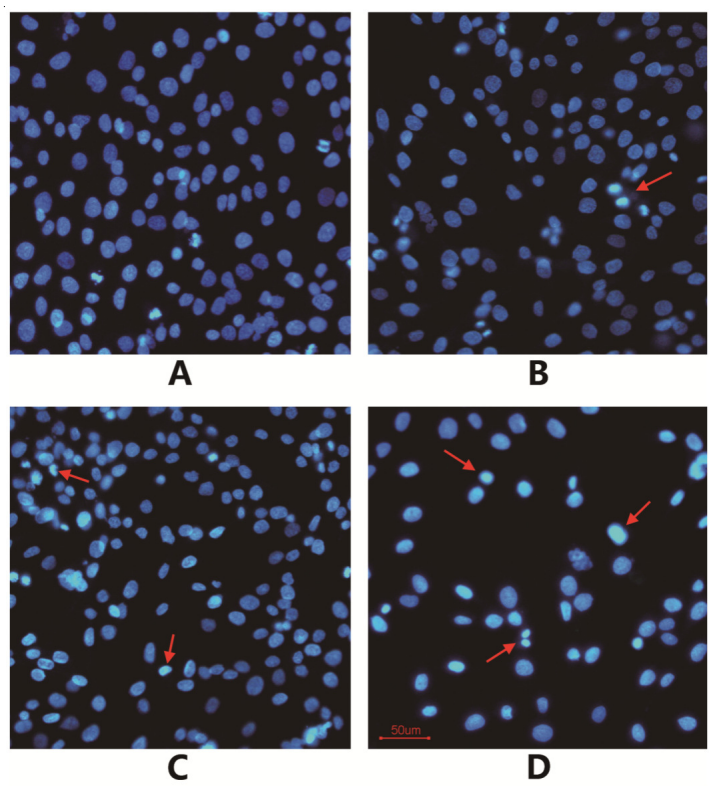

Fig. 4. Morphological changes of MG63 cells treated with paper mulberry fruit extract for $24 \mathrm{~h}$ by Hoechst 33258 staining. Control cells (A) and cells treated with 400,800 and $1600 \mu \mathrm{g} \mathrm{mL}^{-1}$ of the extract (B, $\mathrm{C}$ and $\mathrm{D})$ were observed under fluorescence microscope. Bar, 50 $\mu \mathrm{m}$

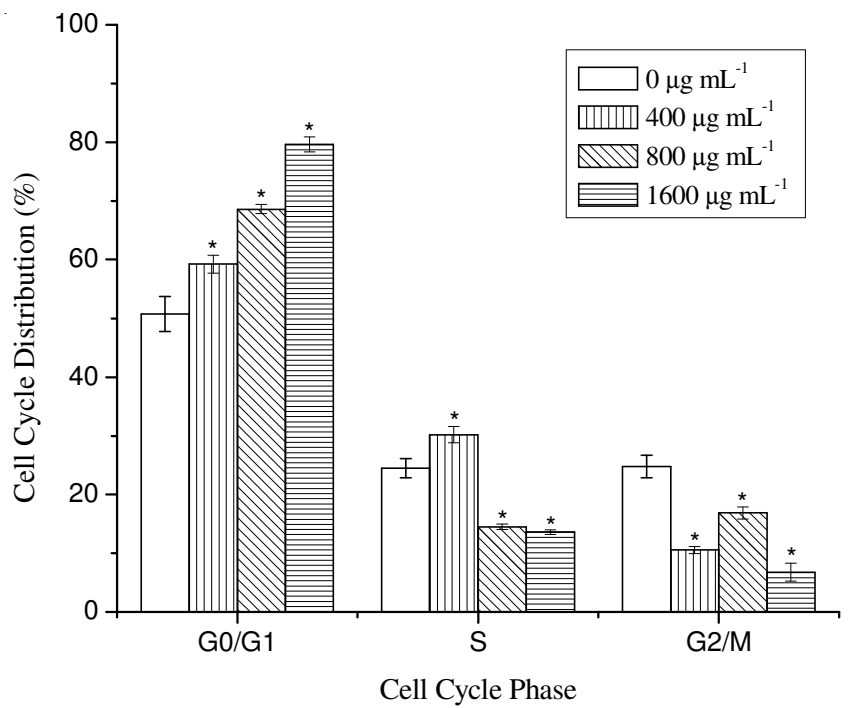

Fig. 5. Flow cytometry analysis of cell cycle distribution of MG63 cells treated with paper mulberry fruit extract for $24 \mathrm{~h}$. Data is expressed as mean $\pm \mathrm{SD}(\mathrm{n}=3) . * p<0.05$ versus control group $\left(0 \mu \mathrm{g} \mathrm{mL} \mathrm{m}^{-1}\right)$

required for proper cell cycle events ${ }^{22}$. Among the CDKs that regulate the cell cycle, CDK2, CDK4 and CDK6 are activated in association with D-type cyclins or cyclin E during the progression of $\mathrm{G} 0 / \mathrm{G}^{23}$. Thus, the extract should affect the expressions of these CDKs and D-type cyclins to the same extent as the plant-derived anticancer agents.

Inhibition of proliferation, morphological apoptotic changes and cell-cycle arrest indicated the cytotoxicity of the extract to Human osteosarcoma MG63 cells. This is the first report about the anticancer activity of the extract and this activity may due to the antioxidant property of the extract. Osteosarcoma is the most common primary bone cancer and the incidence rates for all races and both sexes are 4 for the range $0-14$ years and 5 for the range $0-19$ years per year per million persons in the $\mathrm{USA}^{24}$. The main methods of treatment for osteosarcoma are chemotherapy and surgery, but the recurrence rate is very high $^{25}$. Therefore, a new alternative agent for the prevention and treatment of osteosarcoma is need. In this work, the extract seems to be a potential compound for antineoplastic drug development.

\section{Conclusion}

The ethanolic extract from paper mulberry fruit exhibited potent antioxidant and anticancer activities. These findings suggest that there may be a potential to use the extract to enhance nutrition of food or develop it to antineoplastic drug.

\section{ACKNOWLEDGEMENTS}

This work was financially supported by the National Natural Science Foundation of China (31001012, 31101304, 20802057, 20672086) and the Natural Science Basic Research Plan in Shaanxi Province of China (2012JZ2002).

\section{REFERENCES}

1. K. Pong, Expert Opin. Biol. Ther., 3, 127 (2003).

2. J.A. Ross and C.M. Kasum, Ann. Rev. Nutr., 22, 19 (2002).

3. S. Zafra-Stone, T. Yasmin, M. Bagchi, A. Chatterjee, J.A. Vinson and D. Bagchi, Mol. Nutr. Food Res., 51, 675 (2007).

4. H. Matsuda, H. Cai, M. Kubo, H. Tosa and M. Iinuma, Biol. Pharm. Bull., 18, 463 (1995).

5. E. Ragazzi and G. Veronese, J. Chromatogr. A, 77, 369 (1973).

6. M. Oyaizu, Nippon Shokuhin Kogyo Gakkaishi, 35, 771 (1988).

7. K. Shimada, K. Fujikawa, K. Yahara and T. Nakamura, J. Agric. Food Chem., 40, 945 (1992).

8. K.N. Prasad, J. Hao, J. Shi, T. Liu, J. Li, X. Wei, S. Qiu, S. Xue and Y. Jiang, Innov. Food Sci. Emerg., 10, 413 (2009).

9. Y.L. Liu, L.H. Tang, Z.Q. Liang, B.G. You and S.L. Yang, J. Ethnopharmacol., 131, 1 (2010).

10. B. Peng, Q. Chang, L. Wang, Q. Hu, Y. Wang, J. Tang and X. Liu, Gynecol. Oncol., 108, 173 (2008).

11. X.J. Zhou, R.Q. Mei, L. Zhang, Q. Lu, J. Zhao, A.H. Adebayo and Y.X. Cheng, J. Asian Nat. Prod. Res., 12, 399 (2010).

12. H.W. Ryu, M.J. Curtis-Long, S. Jung, I.Y. Jeong, D.S. Kim, K.Y. Kang and K.H. Park, Food Chem., 132, 1244 (2012).

13 H.Y. Sohn, K.H. Son, C.S. Kwon, G.S. Kwon and S.S. Kang, Phytomedicine, 11, 666 (2004).

14. S.H. Bae and H.J. Suh, LWT-Food Sci. Technol., 40, 955 (2007).

15. J. Dai, A. Gupte, L. Gates and R.J. Mumper, Food Chem. Toxicol., 47, 837 (2009).

16. W.Y. Huang, Y.Z. Cai, Y. Zhang, Nutri. Cancer, 62, 1 (2010).

17. H.J.D. Dorman, A. Peltoketo, R. Hiltunen and M.J. Tikkanen, Food Chem., 83, 255 (2003).

18. Z. Jia, F. Tao, L. Guo, G. Tao and X. Ding, LWT-Food Sci. Technol., 40, 1072 (2007).

19. Y. Frum, A.M. Viljoen and F.R. Van Heerden, S. Afr. J. Bot., 73, 583 (2007).

20. B. Halliwell, Biochem. Soc. Trans., 35, 1147 (2007).

21. Q.F. Li, S.L. Shi, Q.R. Liu, J. Tang, J. Song and Y. Liang, Int. J. Biochem. Cell B, 40, 1918 (2008).

22. J.K. Buolamwini, Curr. Pharm. Design, 6, 379 (2000)

23. C.J. Yang, Y.J. Huang, C.Y. Wang, P.H. Wang, H.K. Hsu, M.J. Tsai, Y.C. Chen, V. Bharath Kumar, M.S. Huang and C.F. Weng, Trans. Res., 155, 305 (2010).

24. G. Ottaviani and N. Jaffe, Cancer Treat. Res., 152, 3 (2010).

25. C.C. Yen, J. Chin. Med. Assoc., 72, 453 (2009). 